\section{Yield Loss and Disease Development of Monilinia fructigena (Aderh. \& Ruhl.) Honey in an Organic Apple Orchard}

\author{
Imre Holb \\ University of Debrecen, Centre for Agricultural Sciences, \\ Faculty of Agricultural Sciences, \\ Department of Plant Protection, Debrecen \\ holb@helios.date.hu
}

\section{SUMMARY}

In a two-year-study, yield loss and temporal development of incidence of Monilinia fructigena were quantified in organic apple orchards and the importance of fruit wounding agents was determined. The first infected fruits were observed at the beginning of August in 2001 and 2002. Disease development was continuous until fruit harvest in both years. Pre-harvest yield loss caused by Monilinia fructigena amounted on average $27.2 \%$ in 2001 and 41.6\% in 2002 by fruit harvest. The growth rate of disease development was almost double in 2002 compared to 2001. All infected fruits were injured by wounding agents such as aboitic and mechanical injury factors, codling moth (Cydia pomonella), common earwig (Forficula auricularia) and birds. In this study, the most important wounding agents were codling moth and mechanical injury factors in organic apple orchards. In both years, our results showed that $70-80 \%$ of the infected fruits were damaged by codling moth in organic apple production. Moreover, $10-15 \%$ of the infected fruits were mechanically injured in the two years. Our results indicated that most of the damaged fruits fell on the orchard floor before harvest and they became an important secondary inoculum source of $\mathrm{M}$. fructigena. Biological and practical implications of the results are discussed.

Keywords: brown rot, disease incidence, epidemiology, Monilinia spp., organic apple, wounding agents

\section{INTRODUCTION}

Monilinia fructigena (Aderh. \& Ruhl.) Honey is an important pathogen causing fruit rot in apple orchards. Losses caused by $M$. fructigena are usually low in conventional and integrated apple orchards (Moore, 1950; Berrie, 1989; Falconi and Mendgen, 1994; van Leeuwen et al., 2000; Xu and Robinson, 2000). Moore (1950) recorded an average of about $9 \%$ of apple fruits becoming infected with $M$. fructigena during the growing season in conventional apple orchards. In a seven-year-study, Berrie (1989) reported mean post-harvest losses in cultivar Cox's Orange Pippin that ranged from $0.1 \%$ to $0.6 \%$ in integrated apple orchards. Van Leeuwen et al. (2000) demonstrated that pre-harvest disease incidence was 4.2-4.3\% in cultivar James Grieve in 1997 and 1998, in cultivar Cox's Orange Pippin this was $4.4 \%$ in 1997 and 2.7\% in 1998. Post-harvest yield loss amounted on average $1.5-2.0 \%$ for both cultivars. Disease incidence of $M$. fructigena has never been reported in organic apple production.

$M$. fructigena penetrates into pre-existing wounds in the fruit skin, although uninjured, ripe apples have been successfully infected via lenticels. Many wounding agents are likely to be responsible for fruit injury in pome fruit orchards, such as aboitic and mechanical factors, codling moth (Cydia pomonella), common earwig (Forficula auricularia), blackbirds (Tordus merula) (Croxall et al., 1951; Lack, 1989; van Leeuwen et al., 2000; Xu and Robinson, 2000). However, no detailed study is available about the role of each wounding agent on infection of $M$. fructigena.

The objective of this study was to quantify the temporal development of disease incidence of $M$. fructigena in organic apple orchards and to determine the importance of mechanical injury factors and of codling moth as wounding agents.

\section{MATERIAL AND METHODS}

\section{Orchard site and plant material}

The study was made in an organic apple orchard at Debrecen-Pallag, Hungary. The 0.5 ha experimental orchard was treated by approved fungicides (copper and wettable sulphur) and insecticides (e.g. Bt products) according to the Hungarian organic production guidelines. The orchard was established in 1997. Trees were planted on M26 rootstock at a spacing of 4 x $1.5 \mathrm{~m}$. Selected cultivars for assessments were cv. Jonagold, Mutsu and Idared.

\section{Assessments}

Disease incidence of $M$. fructigena, injury caused by $C$. pomonella and mechanical injury on fruits were assessed from 15 May until 30 September in 2001 and 2002. Assessments were made in every 1216 days and on all fruits of 14 selected trees on each cultivar. Both the fruits on the trees and the fallen fruits on the orchard floor were assessed and counted. Percentage of disease incidence of $M$. fructigena, of injury caused by $C$. pomonella and of mechanical injury was calculated for each assessment date.

\section{Data analysis}

Collected data for the three cultivars were averaged for each assessment date. Mean data of disease incidence of $M$. fructigena, percentage of injury caused by $C$. pomonella and percentage of mechanical injury on apple fruits were put into a graph separately for 2001 and 2002. All data were subjected to analyses of variance (ANOVA) in order to test the difference of yield loss disease 
development between the two years. Before analyses data were transformed to angular to correct normality. Significant F-tests $(\mathrm{P}<0.05)$ were performed for pairwise comparison of the two years' disease development means.

\section{RESULTS}

Disease incidence of brown rot

The first infected fruits were observed at the beginning of August and disease development was continuous until harvest in both years (Figures 1A and $1 B$ ). Disease incidence was $27.2 \%$ in 2001 and 46.1\% in 2002 by fruit harvest. During the observed period, the speed of disease development was almost double in 2002 compared to 2001. Significant F-test $(\mathrm{P}<0.05)$ showed that disease development in 2001 was not significantly different from that of 2002 at the assessment dates of 3 and 19 August $(\mathrm{P}=0.987$ and $\mathrm{P}=0.435$, respectively) However, the disease development was significantly higher in 2002 compared to that of 2001 at the assessment dates of 31 August, 16 and 29 September $(\mathrm{P}=0.042, \mathrm{P}=0.021$ and $\mathrm{P}=0.008$ ).

Incidence of Cydia pomonella and mechanical injury factors on fruits

All infected fruits were injured by wounding agents probably before infection. From these wounding agents, the $C$. pomonella and mechanical injury were the most important. The injury caused by C. pomonella continuously followed the temporal development of incidence of $M$. fructigena (Figures $1 A$ and $1 B$ ). However, the level of $C$. pomonella was always lower than the incidence of $M$. fructigena. 70 $80 \%$ of the Monilinia infected fruit was damaged by C. pomonella. Mechanical injury remained low in both years (Figures $1 \mathrm{~A}$ and $1 \mathrm{~B}$ ). A small increase of mechanical injury was detected at the last assessment date. $10-15 \%$ of the Monilinia infected fruits were mechanically injured in the two years.

Figure 1: Disease incidence of Monilinia fructigena, percentage of injury caused by Cydia pomonella and percentage of mechanical injury on apple fruits in an organic apple orchard in 2001 (A) and 2002 (B)

(Debrecen-Pallag, Hungary)
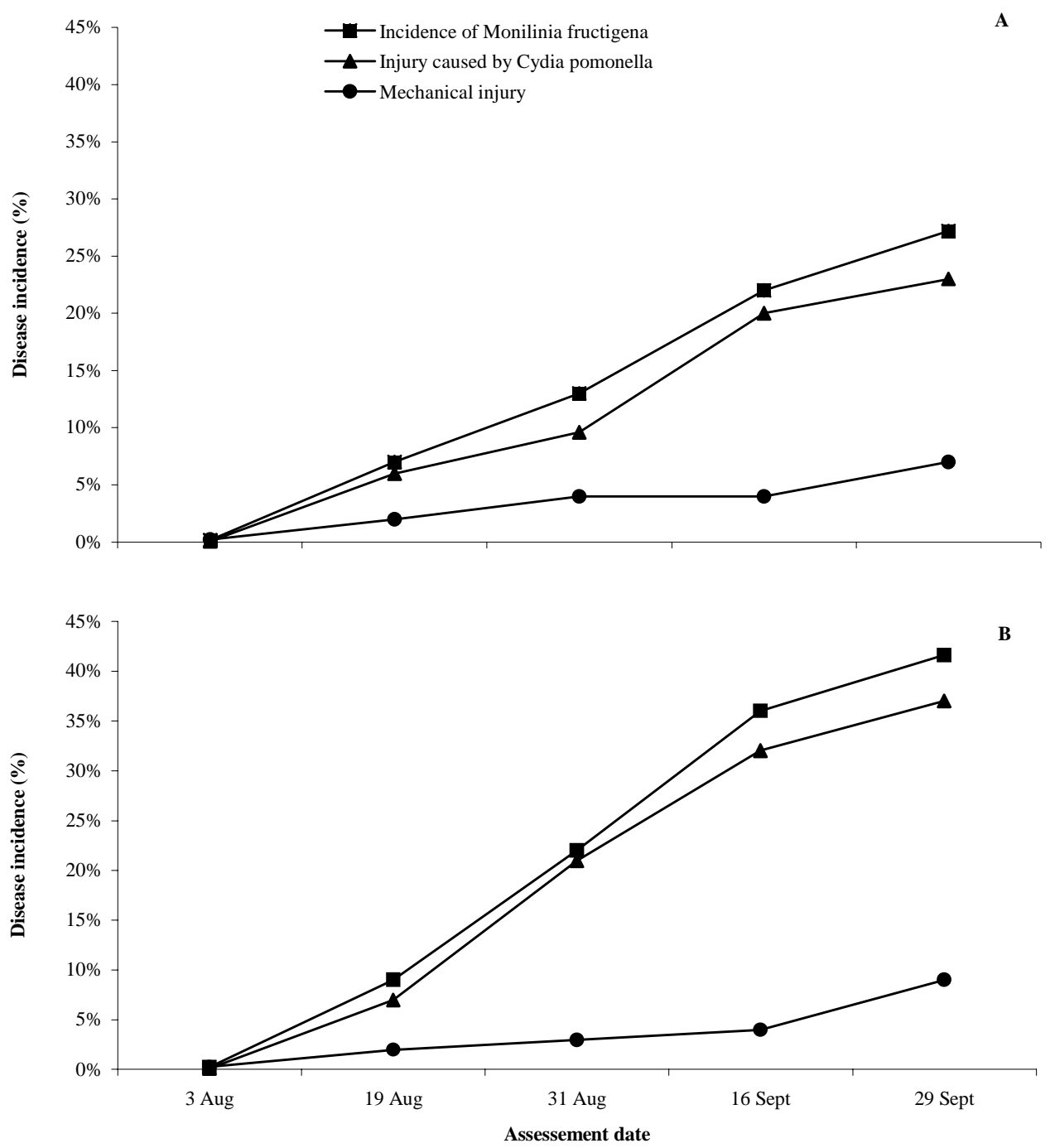


\section{DISCUSSION}

This study demonstrated that large amount of yield loss was detected in an organic apple orchard in 2001 and 2002 at Debrecen-Pallag, Hungary. Disease development started at the beginning of August and most of the diseased fruits were injured by larvae of C. pomonella.

This study showed that first infected fruits could be assessed at the second half of the summer and damage greatly increased by harvest. Moore (1950) and Berrie (1989) also noted that the increase of disease development was assessed from few weeks before harvest until harvest. They concluded that the increasing number of Monilinia infected fruits is due to ripening of the fruits and maybe the increasing sugar content of the fruits. However, Croxall et al. (1951), Lack (1989), van Leeuwen et al. (2000) and $\mathrm{Xu}$ and Robinson (2000) demonstrated that wounding agents and ripening of the fruits are the main factors determining the amount of infection caused by $M$. fructigena. Our data support the above statements, because most diseased fruits were assessed around harvest time and 70-80 percent of the infected fruits were injured by larvae of $C$. pomonella.

According to our results, we suppose that incidences of wounding agents, primarily $C$. pomonella, play an important role in the yield loss and disease development of $M$. fructigena in organic apple orchards. Consequently, disease epidemiology of $M$. fructigena is affected by $C$. pomonella and its effective control greatly reduces the brown rot damage in the orchard and also during storage.

\section{ACKNOWLEDGEMENTS}

The research was partly supported by a János Bolyai Research Fellowship and the Hungarian Scientific Research Fund (OTKA F043503).

\section{REFERENCES}

Berrie, A. M. (1989): Storage rots of apple and pear in South East England 1980-88: incidence and fungicide resistance. In: Gessler, B. K. ed. IOBC Bulletin, Vol. II. Integrated control of pome fruit diseases, Locarno, Switzerland: IOBC, 229-239.

Croxall, H. E.-Collingwood, C. A.-Jenkins, J. E. E. (1951): Obsercation on brown rot (Sclerotinia fructigena) of apples in relation to injury caused by earwigs (Forficula auricularia). Annals of Applied Biology, 38. 833-843.

Falconi, G. J.-Mendegen, D. H. (1994): Epiphytic fungi on apple leaves and their value for control of the post-harvest pathogens Botrytis cinerea, Monilinia fructigena and Penicillium expansum. Journal of Plant Disease and Protection, 101. 1. 38-47.
Lack, H. (1989): The spread of apple brown rot (Monilinia fructigena) by insects. Annals of Applied Biology, 115. 2. 221-227.

Moore, M. H. (1950): Brown rot of apples: fungicide trials and studies of the relative importance of different wound-agents. Journal of Horticultural Science, 25. 225-234.

Van Leeuwen, G. C. M.-Stein, A.-Holb, I.-Jeger, M. J. (2000): Yield loss caused by Monilia fructigena in Dutch orchards. European Journal of Plant Pathology, 75. 534-432.

Xu, X. M.-Robinson, J. D. (2000): Epidemiology of brown rot (Monilinia fructigena) on apple: infection of fruits by conidia. Plant Pathology, 49. 2. 201-206. 